\title{
A Questão Social e Ambiental na Revista Brasileira de Contabilidade: Uma Análise dos Artigos Publicados no Final do Século XX
}

\author{
The Environmental and Social Issues in the Journal of Accounting: An Analysis \\ of Articles Published in the End of the Twentieth Century \\ José Ricardo Maia de Siqueira \\ UFRJ
}

\begin{abstract}
Resumo
Nos últimos séculos, o crescimento industrial, impelido pelo capitalismo, tem consumido recursos com voracidade e a produção de bens e serviços tem gerado externalidades negativas crescentes, pressionando a capacidade de recuperação do planeta ao limite. O final do século XX assistiu a uma pressão crescente por meios de produção menos agressivos e mais inclusivos. Tendo em vista este pano de fundo, esse trabalho tem como objetivo analisar a produção intelectual publicada na Revista Brasileira de Contabilidade (RBC) no período de 1971 a 2000. Este interstício de tempo foi escolhido pois representa um período de mudança nas demandas que emanam da sociedade, o que pode se refletir nos artigos publicados. A RBC foi selecionada por se tratar de um dos periódicos com maior impacto na classe contábil, não se restringindo à área acadêmica. Foram analisados os artigos que continham as palavraschave relativas a aspectos socioambientais nos exemplares pertencentes à Biblioteca Ivo Malhães de Oliveira. Se constatou um aumento no número de artigos com temática socioambiental no período de 1990 a 2000 em relação ao período de 1971 a 1989. Além disso se detectou uma contribuição bastante diversificada no período em questão.
\end{abstract}

Palavras-chave: Responsabilidade Socioambiental. Relatórios Socioambientais. Contabilidade Ambiental.

\begin{abstract}
In recent centuries, the industrial growth, driven by capitalism, has consumed resources in large quantities and the production of goods and services has generated growing negative externalities, pressing the resilience of the planet to the limit. The late twentieth century witnessed a growing pressure by less aggressive and more inclusive means of production. Given this background, this paper aims to analyze the intellectual production published in the Revista Brasileira de Contabilidade (RBC) in the period 1971 to 2000. This period was chosen because it represents a period of change in the demands emanating from society, which may be reflected in published articles. The RBC was selected because it is one of the journals with high impact on the accounting, not restricted to accounting scholars. It has been reviewed the articles that contained the keywords related to environmental aspects in the journals belonging to the Ivo Malhães de Oliveira Library. It has been found an increase in social and environmental related theme articles in the period 1990 to 2000 when in comparison to the period 1971 to 1989. Furthermore it has been detected a very diverse contribution in the analyzed period.
\end{abstract}


Keywords: Environmental Responsibility. Social and Environmental Reports. Environmental Accounting.

\section{INTRODUÇÃO}

Os impactos socioambientais sempre foram uma constante no desenvolvimento econômico da humanidade. Mas nos últimos séculos, com o desenvolvimento do capitalismo, o processo produtivo se acelerou levando a um crescente impacto ambiental, aliado a uma forte disparidade social.

Nos últimos anos do século XX, impulsionados por notícias de aquecimento global, chuva ácida, destruição da camada de ozônio, desmatamento, poluição crescente, redução da biodiversidade, desemprego, perda do poder de compra e aumento da insegurança no trabalho, só para citar alguns fatores; a sociedade começou a direcionar a governos e empresas uma crescente preocupação com as questões socioambientais.

\subsection{Problema de Pesquisa e Objetivo}

Tendo como pano de fundo o recrudescimento dos efeitos nocivos da atividade econômica humana sobre o tecido social e ambiental e a reação da sociedade às consequências desta atividade, surge o seguinte problema de pesquisa: qual o reflexo do crescente questionamento que emana da sociedade em relação aos princípios que norteiam a visão dominante de desenvolvimento na produção intelectual contábil publicada na Revista Brasileira de Contabilidade no final do século XX?

Como resposta a este problema de pesquisa tem-se como objetivo deste trabalho analisar os artigos relacionados à temática socioambiental publicados na Revista Brasileira de Contabilidade no período de 1971 a 2000.

\section{REVISÃO BIBLIOGRÁFICA}

Esta seção se divide em três partes, onde se apresenta um breve histórico das questões socioambientais ao longo dos séculos, se aborda a produção intelectual em contabilidade relacionada à temática socioambiental e se relata os ciclos de publicação da $\mathrm{RBC}$, finalizando este relato abordando o espaço da temática socioambiental na revista.

\subsection{A Atividade Humana e o Impacto Socioambiental}

Há fortes indícios de que algumas tribos indo-européias demonstravam grande respeito pela natureza. É o caso dos celtas, cuja a civilização começou a florescer no século 6 a.C.. Antes de adorar os deuses de seu panteão, eles cultuavam as montanhas, as árvores, as nascentes, os rios e os animais. Em suma, a natureza era o ponto central de suas crenças religiosas (BULLEN et al, 2010, p. 256).

Com o passar dos anos, muita coisa se modificou. No europeu da Alta Idade Média havia um sentimento de hostilidade e agressividade em relação ao misterioso vazio de homens denominado mundo selvagem. Para ele, esse espaço deveria ser domado através da violência 
durante o outono, quando a vegetação encontra-se mais enfraquecida e a floresta mais descoberta (ROUCHE, 2009, p. 475).

Durante o século XVI, poucos anos após seu descobrimento, o Brasil já apresentava uma atividade econômica ambientalmente nociva, pois a retirada das toras de Pau-Brasil "era uma exploração rudimentar que não deixou traços apreciáveis, a não ser na destruição impiedosa e em larga escala das florestas nativas donde se extraía a preciosa madeira" (PRADO JÚNIOR, 1962, p. 26).

No Brasil do século XIX, uma crítica ambiental embrionária já chamava atenção para os desmatamentos. Cunha Mattos, um autor da época, criticava a derrubada de matas e bosques e a subsequente queimada de troncos e raízes para a implantação de plantações, fornalhas e carvoarias. O resultado, destaca ele, é que onde existiam grandes extensões de florestas só restam grandes espaços vazios com campos de erva gramínea ou capoeira fraca, onde os eventuais moradores têm que caminhar léguas para encontrar uma mata (PÁDUA, 2002, p. 178-179).

No Brasil, o período pós-golpe é marcado pela ideia do desenvolvimentismo. A ideia do crescimento é tão presente que suplanta qualquer preocupação ambiental. Esta era uma questão que não se encontrava na pauta de discussão. A Transamazônica rasgou a maior floresta tropical do mundo e a visão do Brasil Grande levou o ufanismo às alturas. Um cronista da época chegou a afirmar que projetos como a Transamazônica, podem levantar eventualmente objeções, mas "são assuntos de êxito garantido, pois não há ninguém que se possa declarar contrário ao progresso econômico e social do país" (BRANCO, 1979, p. 662663).

Anos depois, contudo, este suposto consenso se mostrará inexistente mesmo entre a alta cúpula do regime. Ernesto Geisel, o quarto presidente da ditadura, lhe impõe a pecha de fracasso resultante de uma possível megalomania. Mas, estranhamente, mesmo muitos anos depois, a crítica surge sem qualquer viés ambiental, mas com forte enfoque operacional, já que a estrada se mostrava sem utilidade, pois não "havia gente para povoar aquela área" (D'ARAUJO; CASTRO, 1997, p. 313-314).

Ernesto Geisel, antes de ser presidente da república, esteve à frente de projetos sob controle da Petrobras na região de Cubatão. Esta cidade da Baixada Santista - um importante polo industrial, com diversas indústrias químicas e fábricas de pesticidas - apresentou, nas décadas de 1960 e 1970, um dos mais altos índices mundiais de poluição ambiental, o que a levou a apresentar na década seguinte um alto índice de anencefalia (ausência de cérebro no nascituro), junto com Araucária no Paraná e Rio Grande no Rio Grande do Sul (FORNARI, 2001).

Este crescimento inconsequente com baixíssimos questionamentos de ordem socioambiental - para não dizer inexistentes - mostrou-se com pés de barro. Pois quando o regime militar se despediu em 1985, a inflação atingia a taxa de 223,8\% e a dívida externa chegava a US\$91 bilhões (FAUSTO, 2002, p. 278-279).

$\mathrm{Na}$ interpretação de Sachs (2008, p. 36), o crescimento obtido no período não pode ser chamado de desenvolvimento, pois para ser chamado como tal deve obedecer "ao duplo imperativo ético da solidariedade com as gerações presentes e futuras, e exige a explicitação de critérios de sustentabilidade social e ambiental e de viabilidade econômica". Ou seja, só o desenvolvimento sustentável deve ser entendido como desenvolvimento.

Pode se achar que o crescimento desordenado sem preocupações sociais ambientais são coisas do passado, mas ainda hoje se discute a possibilidade de haver uma subavaliação 
nos custos ambientais da extração de hidrocarbonetos, elemento de fundamental importância para a economia mundial, dada a agressividade de tal atividade. Com frequência, os pontos de extração se localizam próximos a rios e lagos, na plataforma continental ou próximos a áreas de grande biodiversidade. Além disso, o transporte dos produtos através de gasodutos e oleodutos leva ao desmatamento para a passagem das tubulações. Sem esquecer os casos de vazamento, como os que envolveram a Shell na região de Magdalena na Argentina, a Ecopetrol no rio Catatumbo na Venezuela, o navio Nissos Amorgos no Golfo da Venezuela e a Pemex no rio Coatzacoalcos no México, só para citar alguns exemplos (DELGADORAMOS, 2006, p. 78-79).

As disparidades sociais também fazem parte da história da humanidade. Mesmo a Antiga Roma tem seus habitantes pobres vivendo em um amontoado de residências frágeis que punham em risco suas vidas. Tratava-se de uma cidade com contrastes, onde se confundem "as noções de uma grandiosidade moderna e de um simplismo medieval e em que, de repente, uma lúcida antecipação de organização à americana se detém sobre uma visão confusa de labirinto oriental" (CARCOPINO, 1990, p. 42).

A sociedade romana é hierarquizada e muito complexa. Em uma cultura que se expande através das conquistas há obviamente uma classe de escravos, classe essa que alcança uma grande escala no final da República. Mesmo entre os homens livres as fortunas pessoais per se não são suficientes para determinar a posição social do indivíduo. Para ascender às posições mais elevadas da sociedade é necessário ter a posse da terra, sem a qual não haverá prestígio social, mas é de suma importância se demonstrar o valor dos antepassados e as glórias de atos de heroísmo ou da vida pública. Assim, ex-escravos só ascenderiam a posições de destaque na sociedade romana em casos excepcionais, ficando, geralmente, tal escassa honraria para seus descendentes, até que a mácula deste passado julgado desonroso desaparecesse. Mesmo entre os plebeus, as disparidades são gritantes, com o agravante de que não havia qualquer privilégio na distribuição de alimentos para os mais pobres. Os estrangeiros eram considerados inferiores, mesmo que tivessem fortuna (LE ROUX, 2009, p. 74-77).

A prática da escravidão é retomada com intensidade, na conquista do continente americano, sobre os indígenas para fins de colonização. A submissão dos aborígenes é tão marcante que Las Casas (2001, p. 31), Frei que viveu entre os séculos XV e XVI, denunciou que os espanhóis oprimem os índios "com a mais horrível e áspera servidão a que jamais se tenha submetido homens e animais".

Para Salinas (1994, p. 23), no entanto, o golpe mais cruel do processo de conquista do Novo mundo se deu através da propagação de pragas, contra as quais as populações indígenas não tinham defesas. Cortez trouxe a varíola, que junto com a febre tifoide enfraqueceu a resistência dos astecas. Só na região do México Central, a população indígena caiu de aproximadamente 11 milhões em 1519, para cerca de 6,5 milhões em 1540, 4,5 milhões no ano de 1565 e 2,5 milhões em 1597.

Contudo tal quadro não arrefece o ânimo dos portugueses que, ao chegarem no Senegal em 1444, não encontram somente ouro, eles encontram mão-de-obra para ser utilizada em suas atividades mais extenuantes e começa o tráfico de negros africanos, iniciando o maior ciclo escravocrata da humanidade. Para garantir sua supremacia neste comércio infame, edificam uma feitoria fortificada no litoral de Gana chamado Castelo da Mina, que passou a receber milhares de escravos trazidos do interior do continente africano (BUENO, 2003). 
A sociedade brasileira tornou-se tão dependente da mão-de-obra escrava, que só no Brasil "entre a segunda metade do século 16 e o ano de 1850, data oficial da abolição do tráfico negreiro, o número de africanos importados é estimado em 3,6 milhões de pessoas" (SCHWARCZ, 2001, p. 38).

Com o passar do tempo tal prática é abolida em todo mundo, freqüentemente mais por razões econômicas do que propriamente humanísticas. No Brasil o escravismo era freqüentemente associado ao atraso econômico, já que a grande plantação canavieira estava entregue a trabalhadores escravos, famintos, torturados e analfabetos, sendo razão fundamental para a ineficiência desta cultura agrícola e a conseqüente degradação ambiental (PÁDUA, 2002, p. 120-124).

Acrescente-se a isto o medo de uma sublevação de uma população negra numerosa e insatisfeita e um racismo manifestado pelo medo da miscigenação entre os povos e se encontrará a base de alguns discursos abolicionistas (PÁDUA, 2002, p. 124-127).

Este processo de exploração econômica deixou diferentes marcas ao redor do mundo. No Brasil muitas das tribos simplesmente desapareceram ou encontram-se em estado de penúria, com problemas de alcoolismo e prostituição. Os negros e seus descendentes ocupam com frequência a base salarial no país.

O relatório "A Desigualdade Racial no Mercado de Trabalho" - elaborado pelo Dieese, em convênio com o Seade e instituições governamentais - reforça tal visão, demonstrando que a participação dos negros no mercado de trabalho brasileiro continua bem mais precária do que a apresentada pela população não-negra. Em todas as grandes regiões do país, a renda dos brancos supera a dos negros e pardos. O rendimento médio dos trabalhadores brancos foi de 3,8 salários mínimos, enquanto os negros recebem cerca de 2 salários e os pardos, 1,8 (PORTES, 2002).

Não é a toa que a população de negros e pardos representa uma parcela considerável dos excluídos no país. Tem-se hoje no Brasil um total de quase 35 milhões de famílias que vivem com até um salário mínimo per capita, este número representa mais de $60 \%$ das famílias brasileiras (ALMEIDA; MARTIN; LINS, 2011).

Tal histórico demonstra claramente que crescimento econômico não é sinônimo de aumento do bem-estar. Esta é uma forte razão para a afloração nos últimos anos - sem esquecer do marco representado pela Rio 92 - dos fortes questionamentos socioambientais quando se trata do crescimento econômico. O que se busca é o "aproveitamento racional e ecologicamente sustentável da natureza em benefício das populações locais, levando-as a incorporar a preocupação com a conservação da biodiversidade aos seus próprios interesses" (SACHS, 2000, p. 53).

\subsection{A Produção Intelectual Contábil na Área Socioambiental}

A pesquisa contábil no Brasil dá um salto na virada dos séculos XX para XXI. Neste período são criados muitos dos atuais programas stricto-sensu do país, além disso, tem-se em 2001 a criação do Congresso USP de Controladoria e Contabilidade, que em suas duas primeiras edições recebe o nome de Seminário USP de Contabilidade. Logo depois é criada a Anpcont, que congrega os programas de mestrado e doutorado em contabilidade do país. Em 2007 é realizado o primeiro Congresso da Anpcont na cidade de Gramado. Este evento já nasce com a classificação máxima da Capes, acompanhando a mesma pontuação que recebe o Congresso USP. 
Este salto qualitativo não se dá desvinculado das preocupações socioambientais que permeiam a sociedade e, consequentemente, se desenvolve uma temática socioambiental na pesquisa em contabilidade, que já se manifestava antes nos programas stricto-sensu existentes no país.

Em 1984, João Eduardo Prudêncio Tinoco defende uma dissertação intitulada "Balanço Social: Uma Abordagem da Transparência e da Responsabilidade Pública das Organizações". Nela o autor faz uma análise do estágio de então dos balanços sociais e comenta a lei francesa que tornou obrigatória a publicação dos balanços sociais, destacando a ausência da Demonstração de Valor Adicionado, que reputa como uma das informações mais importantes (TINOCO, 1984).

Em 1992, Maisa de Souza Ribeiro tem aprovada sua dissertação de mestrado intitulada "Contabilidade e Meio Ambiente". Nela, dentre outras realizações, a autora chama a atenção que as organizações devem retratar "além da avaliação da evolução econômica da entidade (...), as contribuições e responsabilidades sociais" (RIBEIRO, 1992, p. 46).

Em 1998, Aracéli Cristina de Sousa Ferreira defende a tese de doutorado intitulada "Uma Contribuição para a Gestão Econômica do Meio-Ambiente: Um Enfoque de Sistema de Informações", onde, dentre outras contribuições, chama a atenção para o fato de que "os problemas relacionados ao meio ambiente estão, cada vez mais, sendo objeto de preocupação econômica e social" (FERREIRA, 1998, p. 1).

Diversos artigos aparecem em eventos da área contábil e afins. Cunha e Ribeiro (2004) se propuseram a apresentar estruturas de relatórios sociais usados em outros países e confrontá-los com a realidade brasileira. Para isto se utilizaram de uma pesquisa empírica com 284 organizações que publicaram tal demonstração em 2003. As autoras constataram que algumas empresas publicam a demonstração com objetivos de marketing e que, de um total de 284 empresas, apenas "3 (...) apresentaram informações sobre todos os aspectos" (CUNHA; RIBEIRO, 2004, p. 12). Demonstrando assim uma limitação na abrangência das informações divulgadas.

Silva e Freire (2001) não objetivam efetuar uma análise sobre a qualidade dos balanços sociais brasileiros, mas sim, oferecer uma abordagem que os autores reputam como nova para o balanço social. Contudo, ao desenvolver tal abordagem os autores expõem sua visão das limitações encontradas nos balanços sociais publicados, denominados por eles como Balanço Social Tradicional (BST).

David e Ott (2003) desenvolveram um estudo baseado nos Balanços Sociais de 88 empresas de pequeno, médio e grande porte, referentes ao ano de 2000 , encaminhados à Assembléia Legislativa do Rio Grande do Sul no ano de 2001, visando concorrer ao Prêmio de Responsabilidade Social e ao Troféu de Responsabilidade Social. Dentre as conclusões dos autores destaca-se a constatação de que diferentemente "da contabilidade tradicional, que evidencia ativos e passivos, os Balanços Sociais em sua maioria buscam apenas demonstrar o ativo social das empresas, desconsiderando o outro lado, necessário para haver equilíbrio" (DAVID; OTT, 2003, p. 12).

Pinto e Ribeiro (2004) avaliaram o conteúdo das informações que foram fornecidas pelas maiores indústrias, por número de empregados de Santa Catarina. A amostra inicial contou com 24 empresas catarinenses, mas apenas oito relatórios sociais foram efetivamente analisados. A pesquisa mostrou que o Balanço Social vem sendo bastante difundido entre as empresas estudadas, porém em modelos diferentes; os indicadores divulgados são os mais variados; há ausência de algumas informações relevantes; os dados são de apenas dois 
períodos, fazendo com que os Balanços Sociais deixem de propiciar aos usuários uma utilidade mais ampla. Entre as múltiplas conclusões dos artigos, destacou-se aquela que aponta que a existência de diferentes modelos e a publicação de dados das mais diversas maneiras, impossibilita o usuário de fazer comparações entre empresas. Mesmo o modelo Ibase, já bastante consolidado apresentou diferenças de empresas para empresas. Além disso, foi constatado que: diversas informações relevantes não foram evidenciadas em nenhum relatório; nenhum dos indicadores foi informado por unanimidade pelas empresas; não há um padrão de divulgação da DVA pelas empresas e, por fim, nenhum dos balanços sociais apresentava notas explicativas.

O crescimento da produção acadêmica e seu aumento de qualidade acabou repercutindo na qualidade dos artigos técnicos, voltados para a classe contábil não acadêmica, que tem como um de seus principais instrumentos de divulgação a Revista Brasileira de Contabilidade.

\subsection{A Revista Brasileira de Contabilidade e a Temática Socioambiental}

A Revista Brasileira de Contabilidade (RBC) circulou pela primeira vez, no distante ano de 1912. Sua veiculação pode ser enquadrada em quatro fases distintas: $1^{a}$ fase (1912 a 1921), $2^{a}$ fase (1929 a 1933), $3^{a}$ fase (1971 a 1989) e $4^{a}$ fase (1990 em diante)" (CFC, 1991, p. $65)$.

O primeiro artigo da revista se intitulava 'Contas Commerciaes - Ensaio de Classificação Scientífica' e era de autoria de J. da Costa Sampaio. O trabalho descrevia o conceito geral da contabilidade e terminava com uma classificação das contas comerciais (GONZAGA, 1996, p. 87).

Na segunda fase, que se iniciou no ano de 1929, era Diretor da RBC o conhecido contador Francisco D'Áuria, tendo Ubaldo Lobo como redator-chefe. A revista foi publicada até o ano de 1933 (CFC, 1991, p. 65).

Ela reinicia sua publicação em pleno regime militar, agora como órgão oficial do Conselho Federal de Contabilidade, tendo como presidente o contador Ivo Malhães de Oliveira. Tratava-se de uma revista em busca de seu perfil, que, nas palavras do presidente do CFC, tem como intenção oferecer "uma apresentação moderna e de leitura amena, fugindo, muitas vezes aos assuntos contábeis, procurando envolver e despertar a atenção para sua leitura" (OLIVEIRA, 1971).

A RBC apresentou 71 edições ininterruptamente até 1989, quando, na gestão do Contador Ivan Carlos Gatti como presidente do CFC, foi completamente remodelada, apresentando novo visual gráfico e tendo o sistema de assinaturas instituído, alcançando 40 mil pessoas (GONZAGA, 1996, p. 86).

A revista atende aos mais diversos campos da contabilidade, trazendo artigos sobre custos, auditoria, perícia, ensino da contabilidade, pesquisa contábil, ética e - atenta às demandas sociais - temática socioambiental, entre outras áreas elencáveis. Os artigos na temática socioambiental versam notadamente sobre contabilidade ambiental e relatórios socioambientais.

O tratamento das questões socioambientais é campo potencialmente profícuo para a pesquisa contábil, campo este que, no entendimento de Parker (2010), pode receber contribuições de elementos de uma leitura mais abrangente que englobe aspectos filosóficos, sociológicos e culturais. Jeacle (2009) leva esta imbricação de conhecimentos ainda mais 
longe e destaca o potencial da aproximação da contabilidade com as atividades diárias como um caminho para aprofundar o entendimento da própria contabilidade, estabelecendo conexões com outras áreas do saber, que inclui, inclusive a arquitetura, para citar apenas um exemplo. Percebe-se, portanto, a existência de um grande espaço a ser ocupado por artigos que versam sobre a temática socioambiental na revista.

\section{METODOLOGIA}

Esta pesquisa se classifica, segundo a tipologia proposta por Raupp e Beuren (2003) quanto aos objetivos como exploratória; quanto aos procedimentos ela é pesquisa bibliográfica e, quanto à abordagem do problema, ela é qualitativa.

Ela é exploratória pois pretende proporcionar maior conhecimento sobre o objeto de estudo, além do objetivar conseguir um novo enfoque sobre o assunto em questão (ANDRADE, 1995).

Quanto aos procedimentos ela é bibliográfica porque recorre ao conjunto de conhecimentos armazenados sobre o tema, esperando conseguir não uma simples repetição de opiniões aventadas anteriormente, mas a construção de um arcabouço conceitual sobre o qual se desenvolverá o artigo (ANDRADE, 1995).

É qualitativa pois tem como proposta "descrever a complexidade de determinado problema, analisar a interação de certas variáveis, compreender e classificar processos dinâmicos vividos por grupos sociais" (RICHARDSON, 1999 apud RAUPP; BEUREN, 2003, p. 91).

Para a coleta dos dados foram examinados os exemplares da Revista Brasileira de Contabilidade pertencentes ao acervo da biblioteca Ivo Malhães de Oliveira. Foram examinados 105 exemplares da revista. Só foram analisados em profundidade os artigos que tinham em seu título as seguintes palavras-chave (acompanhadas de suas variações por número): social, socioambiental, ecologia, meio ambiente, ambiental, valor adicionado, valor agregado e riqueza. Só foram relatados os artigos que traziam em seu bojo um enfoque relacionado, minimamente, à temática socioambiental. O título dos artigos, seguido pelo ano de sua publicação, compõem os subtítulos dentro dos períodos de estudo da análise de resultados constante desta pesquisa.

O período em análise vai de 1971 - início da terceira fase de publicação da RBC (CFC, 1991, p. 65) - a 2000, visando captar aspectos significativos em um momento de transição onde ficam mais claras as demandas socioambientais que emanam da sociedade no fim do século XX.

\section{ANÁLISE DOS RESULTADOS}

Os resultados foram analisados cobrindo dois períodos de tempo: de 1971 a 1989 terceira fase de publicação da RBC (CFC, 1991, p. 65) - e de 1990 a 2000.

\subsection{Período de 1971 a 1989}

O período de 1971 a 1989 é de extrema aridez no tocante a artigos relacionados à temática socioambiental. Primeiramente por se tratar de uma revista em busca de sua voz. Nota-se, notadamente nas primeiras edições, uma grande quantidade de material editorial 
diverso, como: notícias, leis, normas, resoluções do CFC, editoriais, avisos aos contabilistas, curiosidades, estatísticas, traduções de artigos estrangeiros, transcrição de artigos e entrevistas, entre outros.

Nos primeiros anos da revista é comum encontrar em suas últimas páginas um espaço humorístico voltado à publicação de charges e quadrinhos em geral. Tal abordagem vai ao encontro das palavras do presidente do CFC que afirma estar a revista "atingindo o ponto por nós desejado, tornando amena a leitura de um órgão que, por sua natureza, se transforma, muitas vezes, em verdadeiro suplício para os que o lêem" (OLIVEIRA, 1972, p. 3)

No tocante aos artigos, eles se centram, no período em questão, em temas voltados a aspectos tradicionais da contabilidade, como: auditoria, contabilidade de custos, controles internos, perícia e ensino da contabilidade, só para citar alguns exemplos. Além disso, os artigos apresentam uma grande diversidade de estruturas, se valem, com frequência, de uma linguagem arcaica e raramente expõem referências bibliográficas. Existem, neste período, artigos que se limitam a escrever pouco mais de duas sentenças e apresentar um gráfico, sem apresentar qualquer tipo de conclusão.

No período em questão somente um artigo resvalou na temática socioambiental, mesmo assim de forma muito subliminar.

\subsubsection{A Importância do Contador no Cenário Econômico e Social - 1980}

O artigo de Franco (1980) destaca o aspecto social de uma grande empresa na sociedade. Ele exemplifica que uma organização empresarial de grande porte emprega de 40 a 50 mil empregados e, consequentemente, ela se torna diretamente responsável pelo bem estar de 200 a 300 mil pessoas.

Assim, conclui Franco (1980, p. 13), a "empresa deixou de ser, portanto, uma entidade que congregue patrimônio e interesse de uma ou algumas pessoas, mas transformou-se em entidade de interesse social".

No entanto, ao longo do artigo ele não dá continuidade à temática, preferindo afirmar que as empresas só conseguiram atingir tal porte devido à atuação do contador, daí a importância social da profissão. Continua o trabalho fazendo críticas sobre a formação dos contadores e como eles devem ser melhor preparados. Critica os técnicos contábeis que tem apenas nível médio. Busca uma convergência entre os detentores do capital e a sociedade. E termina sem falar minimamente sobre mensuração de impactos sociais, ou desenvolver qualquer outro enfoque social.

\subsection{Período de 1990 a 2000}

A produção intelectual sobre a temática ambiental cresce consideravelmente. No período em questão são encontrados 17 artigos. Se percebe ainda que estes artigos apesar de se encontrarem distantes de uma padronização, já não apresentam a grande variedade de estruturas como acontece no período anterior, assemelhando-se um pouco mais ao padrão apresentado pelos artigos acadêmicos que seriam apresentados na primeira década dos anos 2000.

\subsubsection{Contabilidade \& Ecologia: Uma Exigência que se Impõe - 1991}


Trata-se do primeiro artigo que aborda plenamente a temática socioambiental. O artigo apesar de não oferecer qualquer referência bibliográfica está bem escrito e coloca questões interessantes.

Nele Carvalho (1991) exorta os contadores a se afastarem da visão arcaica de escrituradores e assumirem seu papel como profissionais de informação. Para isso recomenda que os contadores estudem conceitos como balanço social, potencialidade de agressão ecológica e técnicas de divulgação.

Destaca uma crítica que se tornará comum em relação aos relatórios de sustentabilidade, o de destacarem os aspectos positivos em detrimento dos negativos, fazendo com que a demonstração se afaste de seu papel de comunicação e se aproxime do perfil de um instrumento de gerenciamento de imagem.

Carvalho (1991, p. 24) faz um paralelo interessante entre lucro e a exploração dos recursos naturais, colocando o conceito de sustentabilidade em termos contábeis. Ou seja só será sustentável a exploração quando o capital natural atingido estiver "como estava no início; em outras palavras, se extraírmos os frutos, acréscimos ou adições ao estoque inicial de recursos, estaremos praticando políticas de crescimento auto-sustentado. E é essa a precisa idéia do lucro "verdadeiro"".

Mais adiante o autor relata cinco passos que as empresas podem adotar para fazer frente aos desafios impostos pela preservação do meio ambiente, sendo que o quinto é de que a empresa "deve REPORTAR os resultados a acionistas, ao governo e à Sociedade que a abriga" (CARVALHO, 1991, p. 25).

\subsubsection{A Quem pertence a Riqueza Criada na Empresa - 1991}

O artigo em questão é pequeno, contendo duas páginas e cinco referências e aborda a Demonstração do Valor Adicionado sob uma ótica social. É interessante destacar que depois de vinte anos praticamente sem qualquer publicação com foco socioambiental, foram encontradas em uma única revista dois artigos. Provavelmente tal fato se deve à realização da Rio-92 no ano seguinte.

Luca (1991) critica a visão tradicional de que ao gerar lucro a empresa maximiza sua contribuição à sociedade. Para a autora, os "instrumentos da contabilidade utilizados até agora têm ignorado o desempenho social das empresas. (...) Os aspectos sociais são tratados, na melhor hipótese, à margem e, em comparação com as informações econômicas, num nível muito mais primitivo" (LUCA, 1991, p. 72).

Destaca o papel do balanço social afirmando que este "vem complementar o sistema de informação contábil, no que se refere à divulgação de informações sobre o desempenho econômico e social da empresa e o seu relacionamento com a sociedade" (LUCA, 1991, p. 72).

Dentro da ideia do balanço social destaca a importância da Demonstração do Valor Adicionado.

\subsubsection{A Contabilidade e o Meio Ambiente - 1991}

Publicado dois números após o artigo de Carvalho (1991), este artigo de Braga (1991) vai ao encontro das ideias propaladas no artigo anterior. Este artigo de apenas uma página e 
sem referências bibliográficas acaba não dando uma contribuição muito diferente daquela apresentada por Carvalho (1991).

\subsubsection{Ecologia Via Contabilidade - 1994}

Este artigo com dez páginas e seis referências bibliográficas apresenta um foco acentuado na discussão de passivos ambientais. Martins e Luca (1994) chamam a atenção para o fato de que as "informações referentes a medidas físicas, quantitativas e qualitativas, de resíduos e seus impactos podem ser evidenciadas no Relatório de Administração ou no Balanço Social" (MARTINS; LUCA, 1994, p. 22).

Mais adiante os autores conceituam passivos ambientais como "benefícios econômicos que serão sacrificados em função da obrigação contraída perante terceiros para preservação e proteção ao meio ambiente" (MARTINS; LUCA, 1994, p. 26).

Chamam atenção ainda para o fato de que as divulgações relativas a assuntos ambientais são qualitativas e parciais, dificultando a comparação entre organizações. Este questionamento viria a ser levantado em diversos trabalhos acadêmicos sobre relatórios sociais em anos vindouros. Termina destacando os grandes desafios que a contabilidade terá que enfrentar para a adequada evidenciação das questões ambientais.

\subsubsection{Ecologia, Meio Ambiente e Contabilidade - 1994}

Neste artigo de oito páginas e com seis fontes bibliográficas, Tinoco (1994) chama atenção para as externalidades negativas, ponto fundamental na discussão relativa a relatórios de sustentabilidade. E se apoia neste ponto para chamar atenção para as demandas que emanam da sociedade. Segundo ele, as empresas "poluidoras estão condenadas, num prazo mais ou menos longo, a desaparecer ou a modificar seu comportamento" (TINOCO, 1994, p. 27).

Retomando uma linha de raciocínio desenvolvida por Luca (1991), Tinoco (1994, p. 31) declara que o "lucro, como a ecologia e o meio ambiente estão provando, não gera necessariamente qualidade de vida". Demonstrando assim sua discordância em relação a uma visão conservadora de empresa. Termina destacando os desafios que se apresentam.

\subsubsection{Contabilidade de Custos para Gestão do Meio Ambiente - 1996}

Neste artigo com oito páginas se destaca a quantidade de fontes bibliográficas utilizadas: um total de 24 . Ferreira (1996, p. 75), com muita propriedade, destaca aqui o paradoxo enfrentado pelas empresas frente às demandas sociais ao afirmar que "mesmo que a sociedade pressione para que não se polua, as empresas terão como um dos fatores limitativos na sua intenção de não poluir, o impacto dos custos que um programa antipoluição terá sobre o curso final de seu produto".

Segue ainda nesta linha ao contrapor a sobrevivência do meio ambiente, como uma questão de médio e longo prazo, onde o impacto de sua ação é visto como pouco significativo; contra a sobrevivência do negócio, uma questão de curto prazo que se faz presente em sua realidade no dia-a-dia.

Se valendo de um recurso já utilizado por Carvalho (1991) traça um paralelo entre a realidade ambiental e contábil ao afirmar que é preciso saber "até que ponto a contabilidade 
está atendendo ao seu princípio maior, que é a Continuidade da Entidade: não a empresa e, sim, numa visão ampla, a entidade Terra" (FERREIRA, 1996, p. 77).

Termina demonstrando que a prática atual ainda se encontra distante daquela que é desejável.

\subsubsection{Balanço Social - 1997}

Neste artigo com nove páginas e sete fontes bibliográficas, Perottoni e Cunha (1997, p. 13) afirmam que o "Balanço Social é um conjunto de informações econômicas e sociais, que tem por objetivo a divulgação de informações sobre o desempenho econômico e financeiro das empresas e sua atuação em benefício da sociedade". Tal afirmativa é um problema. Se se pretende que o balanço social seja um instrumento não tendencioso para mensuração do impacto social de uma organização, este conceito carrega dentro de si uma inverdade ao afirmar que esta demonstração "tem por objetivo a divulgação de (...) sua atuação em benefício da sociedade". O balanço social deve demonstrar não só os efeitos positivos da atividade econômica, mas também seus efeitos daninhos, como a emissão de efluentes, a poluição do ar e a devastação de áreas verdes, por exemplo. O que se deseja obter é uma ferramenta que permita à sociedade perceber se ao longo do processo produtivo, a empresa forneceu uma contribuição social positiva ou negativa. Não se esquecendo, obviamente, de seu papel como fonte de informações para tomada de decisões.

\subsubsection{Considerações sobre a Contabilidade Social - 1998}

A principal contribuição deste pequeno artigo de três páginas e sem qualquer referencial bibliográfico é a informação de que diversos "historiadores elegem a Alemanha como o local onde teria iniciado, na década de 20, o esforço para apresentação de um tipo especial de informe que tomou o nome de Balanço Social" (SÁ, 1998, p. 12). O autor, contudo, não identifica que autores são esses, o que representa um revés para a academia, já que não há consenso em relação a essa informação.

\subsubsection{Balanço Social: Liberdade ou Obrigatoriedade - 1998}

Perottoni (1998, p. 82) neste pequeno artigo de uma única página - e sem qualquer referência - defende a idéia de "que não deveríamos ter uma legislação que tornasse compulsória a divulgação das atividades sociais realizadas pelas empresas". Tal ideia já foi motivo de grande debate na grande imprensa, com grupos opositores expondo seus argumentos e não chegando a um consenso.

$\mathrm{O}$ autor ainda acrescenta que o próprio Betinho, em artigo divulgado em 7 de abril de 1997 no jornal Folha de São Paulo, entendeu ser a voluntariedade o melhor caminho para que a ideia dê certo. Isto é questionável já que a colocação de Betinho se referia a uma situação idealizada.

\subsubsection{Balanço Social: Uma Demonstração da Responsabilidade Social, Ecológica e Gestorial das Entidades - 1998}


Trata-se de outro artigo que surpreende, frente aos demais que constituem a revista, pela quantidade de fontes bibliográficas. Kroetz (1998) se vale de 26 fontes bibliográficas neste artigo de dez páginas.

Já no início do artigo é apresentado um bom conceito de balanço social, que é apresentado como "uma demonstração que permitirá identificar não só a qualidade das relações organizacionais para com os empregados, com a comunidade e com o meio ambiente, como também quantificá-las (nos casos possíveis)" (KROETZ, 1998, p. 44).

Divergindo do que foi apresentado por Sá (1998) que vinculou o surgimento do balanço social na Alemanha da década de 1920, Kroetz (1998) identifica a origem do balanço social na metade do século XX, quando foi estudada e desenvolvida.

Ao longo do texto aborda a questão do projeto de lei sobre balanço social que se encontra em trâmite no Congresso, fazendo sugestões de indicadores. Propõe a implantação conjunta do relatório por parte de empresas e governos. E termina o artigo exortando, na linha apresentada por Ferreira (1996), o contador a não ter apenas um papel passivo de registrar contingências socioambientais, mas ser mais atuante e tendo que "explicar as mutações patrimoniais e elaborar demonstrações que reflitam a realidade do impacto ambiental e social exercido pelas empresas na fabricação de produtos" (KROETZ, 1998, p. 51).

\subsubsection{Balanço Social - 1999}

Este artigo com dez páginas e vinte fontes bibliográficas é aberto remetendo a discussão sobre balanço social para a Associação de Dirigentes Cristãos de Empresa na década de 1960 e mais recentemente para o sociólogo Herbert de Souza e as deputadas Martha Suplicy, Sandra Starling e Maria Conceição Tavares.

Em seguida, Ribeiro e Lisboa (1999) abordam a questão do impacto ambiental das atividades econômicas, para depois defender a inclusão destas informações nas demonstrações contábeis. Por fim, remetem a discussão a mais duas vertentes do balanço social: o balanço de recursos humanos e a demonstração de valor adicionado.

Finalizam afirmando que "a Contabilidade pode contribuir muito com o governo e com a sociedade em geral, na busca de soluções para os emergentes e crescentes problemas sociais" (RIBEIRO; LISBOA, 1999, p. 81).

\subsubsection{Auditoria do Balanço Social - 1999}

Este artigo de Kroetz (1999) conta com 13 páginas e 12 referências bibliográficas. Nele o balanço social é conceituado como uma "demonstração que busca evidenciar (...) o papel que a entidade representa e representará, tanto em seu ambiente endógeno e exógeno" (KROETZ, 1999, p. 21).

Chama atenção para o desenvolvimento de um novo campo na Contabilidade: auditoria do balanço social, contudo, usa os termos auditoria do balanço social e auditoria social como sinônimos, não se aprofundando com considerações adicionais sobre a veracidade de tal afirmação.

Fala sobre o desafio de se construir um modelo de auditoria para o balanço social, traçando considerações sobre sua metodologia e desembocando nas fases deste modelo. 


\subsubsection{A Responsabilidade Social da Empresa: Um Enfoque ao Balanço Social - 1999}

O artigo de Santos e Silva (1999) apresenta 12 referências bibliográficas e oito páginas. Os autores chamam a atenção para a importância do volume de investimentos efetuados na sociedade na determinação do grau de comprometimento da organização com os problemas da sociedade.

\subsubsection{Contabilidade Social - 1999}

Este trabalho, com 11 páginas e 11 referências, destaca diferentes pontos relevantes sobre os relatórios sociais. Primeiramente recorda que o balanço social é ainda um instrumento em desenvolvimento. Em seguida chama atenção para o fato de que Portugal também tornou obrigatória a publicação dessa demonstração, através da Lei 141. Por fim aborda a limitada abrangência daquele instrumento ao destacar que a proposta foi criticada pelos empresários portugueses e destaca que tal "reação poderia ser esperada, uma vez que o Balanço Social português restringe-se ao preenchimento do formulário anexo à lei, englobando uma série de dados sobre a situação dos recursos humanos da entidade, e nada mais." (KROETZ, 1999a, p. 35).

\subsubsection{Considerações Gerais sobre a Contabilidade Aplicada ao Meio Ambiente Natural - 2000}

Neste pequeno artigo com quatro páginas e 12 referências, Sá (2000) lembra a vinculação da empresa com o meio onde está inserida, destaca a necessidade de estabelecer controles internos e um plano de contas que reflita essa relação da empresa com o meio ambiente e define, rapidamente, a composição do balanço ambiental.

\subsubsection{Balanço Social: O Poder de Difusão da Informação - 2000}

Neste artigo de nove páginas e 18 referências, Peixe, (2000, p. 63) afirma que o profissional contábil, frente aos novos desafios, "deve trilhar o caminho do profissional especialista versus profissional generalista para tornar-se um profissional multiespecialista". Há uma discordância aqui com o termo profissional multiespecialista, por ser deveras pretensioso, no entanto, concorda-se com a idéia subjacente de que este profissional para estar apto a desenvolver uma abordagem multiprofissional, "deverá possuir uma visão global do ambiente em que está inserido" (PEIXE, 2000, p. 63).

Além disso, ao contrário do que defende Perottoni (1998), Peixe (2000) defende a existência de uma legislação relativa à publicação dos balanços sociais que se faça saber quais indicadores devem ser elencados e o que exatamente estes devem conter.

\subsubsection{Custos Ambientais: Uma Abordagem Teórica com Ênfase na Obtenção de Vantagem Competitiva - 2000}

O artigo de Wernke (2000) de oito páginas e 17 referências aborda a ênfase contábil na questão ambiental, focando sua análise em cima dos custos ambientais. Para isto chama 
atenção para o uso da defesa do meio ambiente como vantagem competitiva. Nesta linha recorre aos estudos de Porter sobre estratégias competitivas.

\section{CONCLUSÃO}

Da análise dos resultados surgem diversos achados interessantes. Primeiramente, se nota uma melhoria na qualidade dos artigos do período de 1991 a 2000, em relação aos publicados no período de 1971 a 1989. No primeiro período os artigos em sua maioria não apresentam qualquer referência bibliográfica, tem uma estrutura muito diversa, chegando, em casos extremos, a praticamente expor uma figura sem maiores considerações. Os artigos do segundo período estão um pouco mais próximos da estrutura comumente vista em artigos acadêmicos da atualidade.

Em alguns artigos (MARTINS; LUCA, 1994; RIBEIRO; LISBOA, 1999; KROETZ, 1999; PEIXE, 2000; FERREIRA, 1996) fica bem clara a preocupação com os desafios enfrentados pela contabilidade na evidenciação dos aspectos socioambientais. A orientação desta preocupação se modifica um pouco de autor para autor. Em Kroetz (1999) ela se centra no desenvolvimento da auditoria de relatórios sociais. Já Peixe (2000) se preocupa com o desenvolvimento das habilidades dos profissionais.

Algumas das críticas aos relatórios sociais que foram publicadas na primeira década de 2000, já aparecem nesta amostra. O viés para gerenciamento de imagem surge no trabalho de Carvalho (1991). A preocupação com a comparabilidade da evidenciação das questões socioambientais surge no artigo de Martins e Luca (1994). Já a abrangência limitada dos relatórios sociais aparece na crítica feita por Kroetz (1999a) ao balanço social português.

A percepção de que a empresa precisa estar em consonância com o meio onde está inserida aparece com muita clareza nos trabalhos de Tinoco (1994), Sá (2000) e Ferreira (1996). Sendo que esta última não se esquece de apontar o paradoxo vivenciado pelos empresários na conciliação de seu compromisso de longo prazo com o planeta e de curto prazo com a empresa.

O surgimento do balanço social é discutido por Ribeiro e Lisboa (1999), Sá (1998) e Kroetz (1998), mas sem muitos pontos em comum. Os primeiros vinculam o surgimento do relatório no Brasil às discussões da ADCE na década de 1960. Sá (1998) remete o momento para a distante Alemanha da década de 1920. E, por fim, Kroetz (1998) imputa a efeméride a meados do século XX.

Quanto à regulamentação do balanço social tem-se Perottoni (1998) optando pela voluntariedade e Peixe (2000) defendendo sua regulamentação, relembrando os debates na grande imprensa, quando Betinho levantou a questão do balanço social.

Cabe destacar aqui o estranhamento que causa o foco muito mais centrado nas questões ambientais do que nas sociais. $O$ trabalho que mais tendeu para a discussão das questões sociais foi o de Luca (1991). Esta é uma questão que merece ser melhor discutida frente às grandes injustiças sociais vivenciadas pela humanidade na atualidade.

\section{REERÊNCIAS}


ALMEIDA, Cássia; MARTIN, Isabela; LINS, Letícia. Uma Massa de Baixa Renda e Uma Elite Rica. O Globo, 86 (28.390): 10, 30 de abril de 2011.

ANDRADE, Maria Margarida de. Como Preparar Trabalhos para Cursos de PósGraduação: Noções Práticas. São Paulo: Atlas, 1995.

BRAGA, Hugo Rocha. A Contabilidade e o Meio Ambiente. Revista Brasileira de Contabilidade, 20 (77): 58, out/dez 1991.

BRANCO, Carlos Castello. Os Militares no Poder: O Baile das Solteironas. Rio de Janeiro: Nova Fronteira: 1979.

BUENO, Eduardo. Brasil: Terra à Vista!. Porto Alegre: L\&PM, 2003.

BULlEN, Matthew et al. Guia Visual da Mitologia no Mundo. São Paulo: Abril, 2010.

CARCOPINO, Jérome. Roma no Apogeu do Império. São Paulo: Companhia das Letras, 1990.

CARVALHO, Nelson. Contabilidade \& Ecologia: Uma Exigência que se Impõe. Revista Brasileira de Contabilidade, 20 (75): 20-25, abr/jun 1991.

CFC. Uma História de Quase 80 Anos. Revista Brasileira de Contabilidade, 19 (74): 64-65, jan/mar 1991.

CUNHA, Jacqueline Veneroso Alves da; RIBEIRO, Maisa de Souza. Evolução e Diagnóstico Atual do Balanço Social. Anais do $4^{\circ}$ Congresso USP de Controladoria e Contabilidade. São Paulo: 2004. Anais eletrônicos. Disponível em www.congressoeac.locaweb.com.br.

D'ARAUJO, Maria Celina; CASTRO, Celso (Orgs.). Ernesto Geisel. Rio de Janeiro: Editora Fundação Getúlio Vargas, 1997.

DELGADO-RAMOS, Gian Carlo. Questão Ambiental. In: Latinoamericana: Enciclopédia Contemporânea da América Latina e do Caribe. Sader, Emir (Coord.). São Paulo: Boitempo; Rio de Janeiro: Laboratório de Políticas Públicas da UERJ, 2006.

DAVID, Afonso Rodrigo de; OTT, Ernani. Balanço Social: Uma Análise das Informações Evidenciadas pelas Empresas. Anais do $27^{\circ}$ Enanpad. Atibaia: 2003. Texto em CD-ROM.

FAUSTO, Boris. História Concisa do Brasil. São Paulo: Edusp, Imprensa Oficial do Estado, 2002.

FERREIRA, Aracéli Cristina de Souza. Uma Contribuição para a Gestão Econômica do Meio-Ambiente: Um Enfoque de Sistema de Informações. São Paulo: USP, 1998. Tese de Doutorado. 
FORNARI, Ernani. Dicionário Prático de Ecologia. São Paulo: Aquariana, 2001.

FRANCO, Hilário. A Importância do Contador no Cenário Econômico e Social. Revista Brasileira de Contabilidade, 10 (34): 12-17, jul/set 1980.

GONZAGA, Alexandre C. Revista Brasileira de Contabilidade - 100 ${ }^{\mathrm{a}}$ Edição. Revista Brasileira de Contabilidade, 25 (100): 86-87, jul/ago 1996.

JEACLE, Ingrid. Accounting and everyday life: towards a cultural context for accounting research. Qualitative Research in Accounting \& Management, v. 6, n. 3, p. 120-136, 2009.

KROETZ, Cesar Eduardo Stevens. Auditoria do Balanço Social. Revista Brasileira de Contabilidade, 28 (116): 19-31, mar/abr 1999.

KROETZ, Cesar Eduardo Stevens. Balanço Social: Uma Demonstração da Responsabilidade Social, Ecológica e Gestorial das Entidades. Revista Brasileira de Contabilidade, 27 (113): 42-51, set/out 1998.

KROETZ, Cesar Eduardo Stevens. Contabilidade Social. Revista Brasileira de Contabilidade, 28 (120): 28-38, nov/dez 1999a.

LAS CASAS, Frei Bartolomé de. O Paraíso Destruído: A Sangrenta História da Conquista da América. Porto Alegre: L\&PM, 2001.

LE ROUX, Patrick. Império Romano. Porto Alegre: L\&PM, 2009.

LUCA, Márcia Martins Mendes de. A Quem pertence a Riqueza Criada na Empresa. Revista Brasileira de Contabilidade, 20 (75): 72-73, abr/jun 1991.

MARTINS, Eliseu; LUCA, Márcia Martins Mendes de. Ecologia Via Contabilidade. Revista Brasileira de Contabilidade, 23 (86): 20-29, março de 1994.

OLIVEIRA, Ivo Malhães de. Apresentação. Revista Brasileira de Contabilidade, 1 (1): 3, jul/set 1971 .

OLIVEIRA, Ivo Malhães de. Editorial. Revista Brasileira de Contabilidade, 2(3): 3, 1972.

PÁDUA, José Augusto. Um Sopro de Destruição: Pensamento Político e Crítica Ambiental no Brasil Escravista (1786-1888). Rio de Janeiro: Jorge Zahar Editor, 2002.

PARKER, Jenneth. Competencies for interdisciplinarity in higher education. International Journal of Sustainability in Higher Education, v. 11, n. 4, p. 325-338, 2010.

PEIXE, Blênio César Severo. Balanço Social: O Poder de Difusão da Informação. Revista Brasileira de Contabilidade, 29 (122):61-69, mar/ abr 2000. 
PEROTTONI, Marco Antonio. Balanço Social: Liberdade ou Obrigatoriedade. Revista Brasileira de Contabilidade, 27 (110): 82, mar/abr 1998.

PEROTTONI, Marco Antônio; CUNHA, Aromildo Sprenger da. Balanço Social. Revista Brasileira de Contabilidade, 26 (104):12-20, mar/abr 1997.

PINTO, Anacleto Laurino; RIBEIRO, Maísa de Souza. Balanço Social: Avaliação de Informações Fornecidas por Empresas Industriais Situadas no Estado de Santa Catarina. Contabilidade \& Finanças, 15 (36): 21-34, setembro/dezembro 2004.

PORTES, Ivone. Mercado de Trabalho Evidencia Desigualdade Racial. Folha Online. Obtido no site http://www1.uol.com.br/folha/dinheiro em 19 de novembro de 2002.

PRADO JÚNIOR, Caio. História Econômica do Brasil. São Paulo: Brasiliense, 1962.

RAUPP, Fabiano Maury e BEUREN, Ilse Maria. Metodologia da Pesquisa Aplicável às Ciências Sociais. In: BEUREN, Ilse Maria (Org.). Como Elaborar Trabalhos Monográficos em Contabilidade: Teoria e Prática. São Paulo: Atlas, 2003.

RIBEIRO, Maisa de Souza. Contabilidade e Meio Ambiente. São Paulo: USP, 1992. Dissertação de Mestrado.

RIBEIRO, Maisa de Souza; LISBOA, Lázaro Plácido. Balanço Social. Revista Brasileira de Contabilidade, 28 (115): 72-81, jan/fev 1999.

ROUCHE, Michel. Alta Idade Média Ocidental. In: VEYNE, Paul (Org.). História da Vida Privada: Do Império Romano ao Ano 1000. São Paulo: Companhia das Letras, 2009.

SÁ, Antônio Lopes de. Considerações Gerais sobre a Contabilidade Aplicada ao Meio Ambiente Natural. Revista Brasileira de Contabilidade, 29 (122):10-13, mar abr 2000.

SACHS, Ignacy. Caminhos para o Desenvolvimento Sustentável. Rio de Janeiro: Garamond, 2000.

SACHS, Ignacy. Desenvolvimento: Includente, Sustentável, Sustentado. Rio de Janeiro: Garamond, 2008.

SALINAS, Samuel Sérgio. México: Dos Astecas à Independência. São Paulo: Brasiliense, 1994.

SANTOS, Odilanei Morais dos; SILVA, Paula Danyelle Almeida da. A Responsabilidade Social da Empresa: Um Enfoque ao Balanço Social. Revista Brasileira de Contabilidade, 28 (118): 75-82, jul/ago 1999.

SCHWARCZ, Lilia Moritz. Racismo no Brasil. São Paulo: Publifolha, 2001. 
SILVA, César Augusto Tibúrcio e FREIRE, Fátima de Souza. Balanço Social Abrangente: Um Novo Instrumento para a Responsabilidade Social das Empresas. Anais do $25^{\circ}$ Enanpad. Campinas: 2001. Texto em CD-ROM.

TINOCO, João Eduardo Prudêncio. Balanço Social: Uma Abordagem Sócio-Econômica da Contabilidade. São Paulo: USP, 1984. Dissertação de Mestrado.

TINOCO, João Eduardo Prudêncio. Ecologia, Meio Ambiente e Contabilidade. Revista Brasileira de Contabilidade, 23 (89): 24-31, nov 1994.

WERNKE, Rodney. Custos Ambientais: Uma Abordagem Teórica com Ênfase na Obtenção de vantagem Competitiva. Revista Brasileira de Contabilidade, 29 (123): 44-51, mai/jun 2000 . 